\title{
(2) OPEN ACCESS \\ Prevalence of therapeutic use exemptions at the Olympic Games and association with medals: an analysis of data from 2010 to 2018
}

\author{
Alan Vernec 주, David Healy
}

- Additional material is published online only. To view please visit the journal online (http://dx.doi.org/10.1136/ bjsports-2020-102028).

Science and Medicine, World Anti-Doping Agency, Montreal, Quebec, Canada

Correspondence to Dr Alan Vernec, Medical Director Science and Medicine, World Anti-Doping Agency, Montreal, QC H2J 3C8, Canada; alan.vernec@wada-ama.org

Accepted 16 April 2020 Published Online First 6 May 2020
Check for updates

(C) Author(s) (or their employer(s)) 2020. Re-use permitted under CC BY-NC. No commercial re-use. See rights and permissions. Published by BMJ.

To cite: Vernec $A$, Healy D. Br J Sports Med 2020:54:920-924.

\begin{abstract}
Objectives The percentage of athletes with Therapeutic Use Exemptions (TUEs) competing in elite sport and the association with winning medals has been a matter of speculation in the absence of validated competitor numbers. We used International Olympic Committee (IOC) and World Anti-Doping Agency (WADA) data to identify athletes competing with TUEs at five Olympic Games (Games) and a possible association between having a TUE and winning an Olympic medal.

Methods We used the IOC's competition results and WADA's TUE database to identify the number of TUEs for athlete competitions (ACs, defined as one athlete competing in one event) and any associations with medals among athletes competing in individual competitions. We calculated risk ratios (RR) for the probability of winning a medal among athletes with a TUE compared with that of athletes without a TUE. We also reported adjusted $R R\left(R_{\text {adj }}\right)$ controlling for country resources, which is a potential confounder.
\end{abstract}

Results During the Games from 2010 to 2018, there were 20139 ACs and 2062 medals awarded. Athletes competed with a TUE in $0.9 \%(181 / 20139)$ of ACs. There were 21/2062 medals won by athletes with a TUE. The RR for winning a medal with a TUE was 1.13 (95\% $\mathrm{Cl}: 0.73$ to $1.65 ; p=0.54)$, and the $\mathrm{RR}_{\text {adj }}$ was $1.07(95 \%$ $\mathrm{Cl}: 0.69$ to $1.56 ; p=0.73)$.

Conclusion The number of athletes competing with valid TUEs at Games is $<1 \%$. Our results suggested that there is no meaningful association between being granted a TUE and the likelihood of winning a medal.

\section{INTRODUCTION}

The desire for fair and clean competition, without the use of performance-enhancing substances, has been an integral element of sports. ${ }^{12}$ In 1928, the International Amateur Athletics Federation became the first federation to prohibit specific substances (stimulants). ${ }^{34}$ In 1967, the International Olympic Committee (IOC) created a 'Prohibited List' that consisted of stimulants and narcotics. ${ }^{45}$ The World Anti-Doping Agency (WADA) inherited the responsibility of publishing the List in 2004. ${ }^{14}$

As the List grew and included common therapeutic agents, for example, glucocorticoids and insulin, it became clear to sport federations, the IOC and physicians that there was a need for medical exemptions to ensure that athletes with medical conditions would not be unfairly excluded. ${ }^{6}$ The concept of allowing athletes with legitimate medical conditions to compete, now known as Therapeutic Use Exemptions (TUEs), remains widely accepted by athletes and sports authorities. ${ }^{7}$ The process is regulated and well-defined in the World AntiDoping Code ${ }^{8}$ and the International Standard for Therapeutic Use Exemptions (ISTUE); a TUE may be granted only if all the critical ISTUE criteria are met. ${ }^{9}$ All TUE applications are evaluated by a panel of independent physicians, known as a TUE Committee.

There have been occasional comments in the media that elite sport was rife with athletes with TUEs, and suspicion of cheating was cast on these athletes. ${ }^{10-12}$ In a survey of Danish athletes in 2013, there was a perception that those with TUEs had an unfair advantage. ${ }^{13}$ WADA previously reported that during the 2016 Summer and 2018 Winter Olympic Games (Games), with 11303 and 2922 competing athletes, respectively, $\sim 1.2 \%$ had valid TUEs in each Games. ${ }^{14}$ Although the number of athletes with TUEs was low, theoretically it was possible that every athlete with a TUE could have won a medal. Therefore, our objectives were to describe the prevalence of TUEs at the five Games between 2010 and 2018 and to assess if athletes who had been granted a TUE were more or less likely to win a medal compared with athletes without a TUE.

\section{METHODS}

Data were collected and analysed from two sources. First, data were retrieved on all TUEs recorded in the WADA Anti-Doping Administration and Management System (ADAMS) database from 2010 to mid-2018. Second, IOC data was obtained for all athletes who competed in the three Winter (2010, 2014 and 2018) and two Summer (2012 and 2016) Games. The data sources are described in more detail later.

This report falls within the scope of Article 2.5 of the Canadian Tri-Council Policy Statement on the Ethical Conduct for Research Involving Humans ${ }^{15}$ and it is considered a quality assurance project that does not require ethics approval.

\section{IOC data}

The IOC data provided information on every athlete competing in every event in each of the five Games in this study. These data included the athlete's name, gender, year, Games, sports discipline, event, country of origin and final ranking.

We restricted data to those events where athletes competed individually, excluding any events requiring two or more athletes, for example, synchronised diving, relays and team sports. We excluded equestrian athletes as this gender-neutral 
sport could not be categorised into men or women. There were no TUEs among equestrian athletes. Athletes who were registered but did not actually compete in a Games event were also excluded.

\section{WADA ADAMS data}

The ADAMS data included information about TUEs that were valid for Games between 2010 and 2018. We extracted the athlete's name, gender, date of birth, TUE effective and expiry dates and the prohibited substance for which the TUE was granted. We considered athletes to have a TUE for the Games only if it was valid at any time between the opening and closing of these Games.

\section{Linking of data sources}

The ADAMS and IOC data were linked by matching the last name, first name and gender. First, only exact matches were included. Any athlete who was not an exact match was then manually checked and only matched if there was only one possible pairing. After matching was completed, the data were anonymised before conducting analyses.

\section{Classes of prohibited substances and methods}

Prohibited substances were classified according to the substance classes defined in the Prohibited List. ${ }^{16}$ Each substance is included in one of nine substance categories S1-S9, with one additional category, P, for drugs prohibited only in some sports. Prohibited methods are covered in M1-M3. ${ }^{16}$ Insulin was extracted and reported separately because it used to be in S2, but is now categorised in S4. As the List changes over time, we included only those drugs that were prohibited at the time of each of the Games. The most significant change was the removal of some inhaled beta-2 agonists (B2A) from the S3 class in 2010 and 2012. In some cases, TUEs were granted for medications that no longer required TUEs. We considered these as TUEs in our analysis because they would have been considered TUEs in previous reports claiming that TUEs led to increased medals.

\section{Countries differentiated according to resources}

Athletes from countries with more resources are generally expected to produce better performance due to higher quality and more effective training, coaches, facilities and so on. ${ }^{17} 18$ Since they are also more likely to have easier access to quality medical care than those from less resourced countries, they are more likely to be diagnosed with a valid medical condition and granted a TUE. To account for this potential confounding, the countries that athletes competed for (Sport Nationality in the IOC data) were classified into one of three categories based on country resources. We defined resources in two ways. First, they were grouped based on the number of athletes sent to the Games, because the Olympic team size has been shown to be the best single predictor of Olympic medals. ${ }^{18}$ Countries sending larger teams generally invest more resources in sport. The cutoff for each category was decided a priori as $<50,50-250$ and $>250$ athletes, representing the sum of all athletes sent to the five Games. Second, the countries were grouped according to their annual gross domestic product (GDP) in 2017 as a proxy for wealth, using data available from the United Nations. ${ }^{19}$ The cut-offs were a priori: US $\$<100$ billion, US $\$ 100-400$ billion and US $\$>400$ billion.

\section{Statistical analysis}

We provided a descriptive analysis that includes the number and percentage of athlete competitions (ACs) with TUEs. An AC was defined as one athlete competing in one event. We stratified by gender for each Games, each substance class and each resource category (as defined earlier). We recorded the number of ACs with TUEs by sport (with specific disciplines for some sports) across all Games. We also subcategorised some sports into endurance (aerobic capacity primary factor for success) and nonendurance with the intent to see if there was an association with B2A TUEs. The categorisation was based on exercise physiology and information provided by experts in sport organisations.

To assess if being granted a TUE affects the chance of winning medals, the probability of winning a medal with a TUE versus that of winning a medal without a TUE was calculated for each event. In this analysis, we used the number of athletes in each event as the denominator. If one athlete competed in three events, he/she had the opportunity to win three medals. Therefore, ACs were used as the denominator in a similar way to how 'athlete exposures' are used in injury analyses. We first calculated unadjusted risk ratios (RR) using a generalised linear model analysis and a log link. In preliminary analyses, a mixed model with a random effect for the athlete did not work because there were too many athletes who competed only once. Then, we conducted a similar analysis with the independent variables being a valid TUE and country resources to account for potential confounding due to country resources. For country resources, we used the total number of athletes competing for each country over the five Games as our primary analysis. As a sensitivity analysis, a similar analysis based on country GDP was applied.

We used medal winners as the outcome of performance to be consistent with previous analyses and debates referring to TUEs and the likelihood of winning medals. ${ }^{20}$ However, from a technical perspective, the generalised linear models we used assume a binomial distribution for the outcome. However, this is not the case in Olympic competitions, where only three medals can be won in an event. A non-parametric analysis examining the effect of TUEs on ranking within a competition would be possible, but it only determines if the rankings from the two groups are different and does not address the question of winning medals. More complicated parametric models have been suggested ${ }^{21-23}$ but they require other assumptions and have never been used to determine medal counts so our results could not be compared with others. Therefore, in this article, we restricted our analyses to those previously used in the sport medicine literature to allow comparisons with previous results. Finally, one reviewer requested sample size calculations. We used all available data on TUEs and performances that were considered valid. This represents a finite population; standard sample size/power calculations would suggest larger sample sizes than are really necessary. Furthermore, the data are not binomially distributed. Power calculations, due to a fixed sample size based on traditional methods that underestimate power, suggest that our study would have $84 \%$ power to detect a RR of 1.75 .

\section{RESULTS}

\section{Number and prevalence of ACs and TUEs at the Games}

There was a total of 12037 athletes competing in individual events at the five Games. As we considered an athlete competing in two different Games as two different athletes, there were 15361 athletes across all Games for analyses. In addition, 21\% of athletes competed in more than one event, and $2 \%$ competed in at least four events, yielding a total of 20248 ACs across 
Table 1 AC TUEs in five Summer and Winter Olympic Games 20102018

\section{AC TUEs for each Games*}

$\mathrm{N}$ (\% of total AC TUEs)

\begin{tabular}{lrlr}
\hline Games & \multicolumn{1}{l}{ Male } & \multicolumn{1}{l}{ Female } & \multicolumn{1}{l}{ Total } \\
\hline 2010 -Winter & $40(2.4 \%)$ & $12(0.9 \%)$ & $52(1.7 \%)$ \\
\hline 2012 - Summer & $19(0.6 \%)$ & $11(0.5 \%)$ & $30(0.6 \%)$ \\
2014 -Winter & $21(1.2 \%)$ & $17(1.2 \%)$ & $38(1.2 \%)$ \\
2016- Summer & $15(0.5 \%)$ & $29(1.3 \%)$ & $44(0.8 \%)$ \\
2018 -Winter & $7(0.4 \%)$ & $10(0.7 \%)$ & $17(0.5 \%)$ \\
All Years Combined & $102(0.9 \%)$ & $79(0.9 \%)$ & $181(0.9 \%)$ \\
\hline
\end{tabular}

*The total number of ACs across genders and all Games was 20139. The ACs for each Games (male,

female and total) are not shown.

AC TUEs, Athlete-competition Therapeutic Use Exemptions.

all the Games. As previously mentioned, we excluded the 109 equestrian events. This left 20139 ACs for the analysis.

The total number of ACs with TUEs (table 1) was 181. In the two Summer Games, the overall percentage of ACs where the athletes had TUEs was $0.6 \%$ and $0.8 \%$, respectively. In the three Winter Games, the percentage of ACs where all athletes had TUEs decreased from $1.7 \%$ to $1.2 \%$ and to $0.5 \%$, respectively.

\section{Prevalence of AC TUEs by Prohibited List class (substance or} method)

The number of AC TUEs for each substance class ranged from $0 \%$ to $0.5 \%$ across all substances and for each gender (table 2 ). In table 2, the total number of TUEs is 215 , which is different from the 181 athletes with at least one TUE in a competition as mentioned in table 1. If, for example, an athlete had three TUEs (eg, S1, S2 and S3) and competed in one AC, they would be counted three times as mentioned in table 2, but only as one $\mathrm{AC}$ as mentioned in table 1. A total of 93 out of 215 TUEs were for inhaled B2A, and 64 of them were prior to 2016. There has been a steady decrease in AC B2A TUEs since 2010 (see online supplementary appendix B).

\section{Prevalence of AC TUEs by sport}

Table 3 shows the number of AC TUEs per sport. Sports with two AC TUEs or less were not included due to privacy concerns. Inhaled B2A AC TUEs were mostly granted in endurance events, except for aquatics. This may be due to elite swimmers'
Table 3 Individual AC TUEs for sports with three or more AC TUEs in five Summer and Winter Olympic Games 2010-2018

\begin{tabular}{|c|c|c|c|}
\hline Sport & $\begin{array}{l}\text { Total number of } \\
\text { AC TUEs }\end{array}$ & AC TUEs for B2A & Other AC TUEs \\
\hline Aquatics-all events less than $400 \mathrm{~m}$ & 10 & 8 & 2 \\
\hline Aquatics (E)-( $\geq 400 \mathrm{~m})$ & 5 & 2 & 3 \\
\hline Athletics $-1500 \mathrm{~m}$ or less; field events & 5 & 0 & 5 \\
\hline Athletics (E)—(>1500 m) & 6 & 1 & 5 \\
\hline Biathlon (E) & 13 & 13 & 0 \\
\hline Bobsleigh & 3 & 2 & 1 \\
\hline Cycling—track, BMX, mountain & 4 & 3 & 1 \\
\hline Cycling (E)-road & 8 & 8 & 0 \\
\hline Golf & 3 & 1 & 2 \\
\hline Gymnastics & 5 & 0 & 5 \\
\hline Shooting & 9 & 0 & 9 \\
\hline Skating—figure and short track & 6 & 3 & 3 \\
\hline Skating (E)—long track & 6 & 4 & 2 \\
\hline Skiing—all other disciplines & 36 & 13 & 23 \\
\hline Skiing (E)—cross-country and Nordic & 41 & 30 & 11 \\
\hline Tennis & 6 & 2 & 4 \\
\hline Wrestling & 3 & 0 & 3 \\
\hline
\end{tabular}

prolonged exposure to chlorine by-products or ozone in indoor pools which can lead to airway dysfunction. ${ }^{24}$ The marathon events had no AC TUEs for B2A. In interpreting the prevalence of AC TUEs in swimming, one should note that some of these athletes compete in over a dozen individual events at multiple Games.

Skiing had the most TUEs of all sports $(n=77)$, which is expected due to the high volumes of cold air inhaled. ${ }^{25}{ }^{26}$ There were 41 in endurance and 36 in non-endurance events. Winter endurance sports (cross-country, Nordic skiing and long-track skating) had a total of 47 AC TUEs for B2A.

Prevalence of AC TUEs by number of competing athletes (as a proxy for country resources)

The results in table 4 support the hypothesis that the country may be an important confounder when examining the relationship between TUEs and medals. Athletes from lower resource countries were less likely to have TUEs compared with athletes from the highest resource countries (low vs high $\mathrm{RR}=0.33(95 \%$

Table 2 Athlete-competition Therapeutic Use Exemptions by substance and method class as defined in the WADA's Prohibited List over five Summer and Winter Olympic Games 2010-2018

\begin{tabular}{|c|c|c|c|c|}
\hline WADA's Prohibited List class & Substance or method & $\begin{array}{l}\text { Male athletes } \\
\text { N (\%) }\end{array}$ & $\begin{array}{l}\text { Female athletes } \\
\mathrm{N}(\%)\end{array}$ & $\begin{array}{l}\text { All athletes } \\
\mathrm{N}(\%)\end{array}$ \\
\hline S1 & Anabolic Agents & $0(0 \%)$ & $2(0.02 \%)$ & $2(0.01 \%)$ \\
\hline S2 & Peptide hormones, growth factors, related substances and mimetics & $8(0.07 \%)$ & $3(0.03 \%)$ & $11(0.05 \%)$ \\
\hline S3 & Beta-2 Agonists & $59(0.51 \%)$ & $34(0.39 \%)$ & $93(0.46 \%)$ \\
\hline S4 & Hormone and metabolic modulators & $5(0.04 \%)$ & $3(0.03 \%)$ & $8(0.04 \%)$ \\
\hline S2/S4 & Insulin (changed categories) & $13(0.11 \%)$ & $2(0.02 \%)$ & $15(0.07 \%)$ \\
\hline S5 & Diuretics and masking agents & $1(0.01 \%)$ & $2(0.02 \%)$ & $3(0.01 \%)$ \\
\hline S6 & Stimulants & $4(0.03 \%)$ & $21(0.24 \%)$ & $25(0.12 \%)$ \\
\hline S7 & Narcotics & $3(0.03 \%)$ & $2(0.02 \%)$ & $5(0.02 \%)$ \\
\hline S8 & Cannabinoids & $0(0 \%)$ & $0(0 \%)$ & $0(0 \%)$ \\
\hline S9 & Glucocorticoids & $30(0.26 \%)$ & $17(0.2 \%)$ & $47(0.23 \%)$ \\
\hline M1 & Manipulation of blood and blood components & $0(0 \%)$ & $0(0 \%)$ & $0(0 \%)$ \\
\hline M2 & Chemical and physical manipulation & $1(0.01 \%)$ & $5(0.06 \%)$ & $6(0.03 \%)$ \\
\hline M3 & Gene and cell doping & $0(0 \%)$ & $0(0 \%)$ & $0(0 \%)$ \\
\hline P1 & Beta blockers (prohibited only in some sports) & $0(0 \%)$ & $0(0 \%)$ & $0(0 \%)$ \\
\hline
\end{tabular}


Table 4 Number and percentage of AC TUEs for countries based on team size in five Summer and Winter Olympic Games 2010-2018

\begin{tabular}{llll}
\hline Tier & $\begin{array}{l}\text { Male } \\
\mathrm{N}(\%) \text { AC TUEs }\end{array}$ & $\begin{array}{l}\text { Female } \\
\mathrm{N}(\%) \text { AC TUEs }\end{array}$ & $\begin{array}{l}\text { Total } \\
\mathbf{N}(\%) \text { AC TUEs }\end{array}$ \\
\hline$>250$ athletes & $91(1.1 \%)$ & $69(1.0 \%)$ & $160(1.1 \%)$ \\
50-250 athletes & $9(0.4 \%)$ & $8(0.6 \%)$ & $17(0.4 \%)$ \\
$<50$ athletes & $2(0.3 \%)$ & $2(0.5 \%)$ & $4(0.3 \%)$ \\
\hline
\end{tabular}

AC TUEs, Athlete-competition Therapeutic Use Exemptions.

CI 0.10 to 0.77$), \mathrm{p}=0.03$; middle vs high $\mathrm{RR}=0.42$ (95\% CI 0.25 to 0.67$), \mathrm{p}<0.01)$.

\section{Prevalence of AC TUEs by country}

The number of AC TUEs among the highest resource countries is illustrated in online supplementary appendix A. Austria had 3.6\% of ACs with TUEs, followed by Denmark with 3.3\%, Norway $3 \%$, Switzerland $2.6 \%$, Slovenia $2.5 \%$ and New Zealand and the USA with $1.7 \%$ each.

\section{Does having a TUE increase the likelihood of winning a medal?}

The total number of medals in individual sports available to be won across all Games was 2062. Athletes with TUEs won 21 of them. The unadjusted (and biased) RR of winning a medal with a TUE over winning a medal without a TUE is 1.13 (95\% CI 0.73 to $1.65 ; p=0.54$ ). After adjusting for country resources (by the number of athletes), the RR for winning a medal with a TUE decreased to 1.07 (95\% CI 0.69 to $1.56, \mathrm{p}=0.73)$. Our sensitivity analysis categorising the country resources by GDP yielded qualitatively similar results $(1.10 ; 95 \%$ CI 0.71 to 1.60 , $\mathrm{p}=0.63$ ). These small point estimates with wide CIs and large $p$ values suggest that there is little evidence that having a TUE increases the likelihood of winning a medal.

\section{DISCUSSION}

The percentage of AC TUEs across all five Games was 0.9\%. AC TUEs for B2A were the most common of all AC TUEs (43\%), followed by those for glucocorticoids (22\%). Athletes with TUEs for individual sports won 21 medals out of a possible 2062 (1\%). Both our unadjusted and adjusted results for country resources had large uncertainty and were not statistically significant $(\mathrm{p}>0.6)$.

Inhaled B2A (S3) are commonly used because of the high general prevalence of asthma in elite athletes competing in endurance events. ${ }^{27}$ The IOC Consensus Statement on Asthma in Elite Athletes recognised that endurance exercise itself is capable of increasing the risk of airway dysfunction. ${ }^{28}$ The epithelial damage to the airways is due to high respiratory rates in dry and cold air or polluted environments, including pollutants in the air immediately above swimming pools. ${ }^{24} 26{ }^{29}$ It has been proposed that the harder one trains, the greater the likelihood of both airway dysfunction (requiring treatment) and improved performance. ${ }^{25}$ There may also be a genetic component to those who sustained damage to their airways. ${ }^{30}$ TUEs were more prevalent in winter sports and therefore countries with increased participation in winter sports had more TUEs, although this has decreased in recent Games.

Glucocorticoids were the second most common therapeutic agents for which TUEs were granted, ${ }^{31}$ followed by stimulants. Stimulant TUEs were predominately for the treatment of attention-deficit hyperactivity disorder (ADHD) but also included anaphylaxis and narcolepsy. There were no TUEs for testosterone, androgenic-anabolic steroids or erythropoiesisstimulating agents.

\section{TUEs and medals}

A report on athletes competing with TUEs for B2A during the 2002-2010 Games showed a higher likelihood of winning a medal compared with athletes without TUEs for B2A. However, the author suggested that athletes who were trained in particular environments were more likely to develop symptoms of asthma and thus be prescribed B2A. ${ }^{20}$ This would be expected to occur in countries with more resources, that is the country is a confounder. Generally, wealthier countries with larger Olympic teams win more medals as a result of better support for sportrelated activities. ${ }^{1718}$ Our results support this theory.

Our study population had 20139 ACs with 2062 medals available. Our unadjusted results for the likelihood of an athlete winning a medal with a TUE versus without one suggested a $\mathrm{RR}=1.13(95 \%$ CI 0.73 to $1.65 ; \mathrm{p}=0.54)$. After adjusting for the confounder country resources, the RR decreased to 1.07 (95\% CI 0.69 to 1.56), and the $\mathrm{p}$ value increased to 0.73 . With such wide confidence intervals and high $\mathrm{p}$ values, there is no evidence that athletes competing with TUEs are more likely to win medals.

\section{Limitations and strengths}

Our results should be interpreted in the context of the study limitations. All TUEs of national-level and international-level athletes, including those granted at major games such as the Olympics, must be entered into ADAMS as per WADA regulations. However, some TUEs may never have been recorded in ADAMS.

Our number of TUEs is lower than that in other reports. We considered only TUEs valid between the opening and the closing of the Games. Previous papers generally considered a TUE valid if it was in force at any time after the opening of the Olympic Village, which is a few weeks earlier. Both our analyses and previous analyses assumed that any TUE granted was valid during the athlete's actual competition(s). If an athlete competed with TUEs during some competitions but not others in the same Games, they would have been considered to have valid TUEs for all these competitions. If, for example, an athlete had a valid TUE for the first week of the Games but did not compete until the last week, this would still be counted as an AC TUE even though the athlete did not compete with a TUE.

Our analyses are restricted only to individual sports because it is unclear how much influence one athlete with a TUE would have on the results in team competitions. Our results are restricted to having a TUE and not the effect of drugs, as some athletes may take a prohibited therapeutic substance without a TUE. We were unable to conduct a repeated measures analysis (accounting for the same athlete competing in multiple events or multiple games) because the majority of athletes competed in only one event. It is recognised that in some sports (eg, swimming, gymnastics and skiing), there is a higher likelihood that athletes compete in more than one event, with or without a TUE.

Our adjustment for the confounder country resources was based on the country the athlete competed for at the Games. Some athletes from less resourced countries may have had access to more support, for example, through scholarships in countries with more resources. This means our results were not able to account for all the confounding (ie, residual confounding remains), and therefore our adjusted RR of 1.07 may still be overestimated. In addition, in the lowest resourced 
country category, there were only four TUEs when categorised by number of athletes and only three TUEs when categorised by GDP, which could lead to sparse data bias. ${ }^{32}$ If this bias exists, then our results would again represent an overestimate of the true value and there is even less evidence that TUEs affect winning a medal. ${ }^{32}$ We were unable to adjust for potential confounders for medical conditions as we only knew those who had a TUE and not those with medical conditions without a TUE.

\section{CONCLUSION}

In the five Games between 2010 and 2018, only a small percentage $(<1.0 \%)$ of athletes competed in individual events with a TUE. After accounting for the different resources available to the athletes, there was little evidence of an increased likelihood of an athlete winning a medal with a TUE compared with that of athletes without TUEs.

\section{What are the new findings?}

- The number of athletes competing with a Therapeutic Use Exemption (TUE) in each individual Olympic event from 2010 through 2018 was calculated.

- During the five Olympic Games, less than $1 \%$ of athletes competing in individual events had a TUE.

- Athletes from countries with greater resources (using country GDP and team size as proxies) are more likely to be granted TUEs and to win medals.

- There was no evidence of increased likelihood of an athlete winning a medal with a TUE compared with athletes without TUEs.

\section{How might it impact on clinical practice in the future?}

- Sport physicians may reassure their athletes that the TUE process is well-controlled and regulated, and there is no rampant use of TUEs in elite sport. There is no unfair advantage for those athletes with diagnosed medical conditions taking a prohibited substance.

Acknowledgements The authors would like to acknowledge the contributions of Andrew Slack, Katharina Grimm, David Gerrard and Katja Mjøsund.

Contributors Each of the authors contributed to the writing and revision of this manuscript.

Funding The authors have not declared a specific grant for this research from any funding agency in the public, commercial or not-for-profit sectors.

Competing interests AV and DH both work for the World Anti-Doping Agency.

Patient and public involvement Patients and/or the public were not involved in the design, or conduct, or reporting, or dissemination plans of this research.

Patient consent for publication Not required.

Provenance and peer review Not commissioned; externally peer reviewed.

Data availability statement Data may be obtained from a third party and are not publicly available. Unfortunately we are not able to make the information publicly available. The Games data were obtained from a third party, the International Olympic Committee. The Therapeutic Use Exemptions data are sensitive medical information from the World Anti-Doping Agency (WADA) Anti-Doping Administration and Management System database and are subject to the WADA International Standard for Protection of Privacy on Privacy and Personal Information.

Open access This is an open access article distributed in accordance with the Creative Commons Attribution Non Commercial (CC BY-NC 4.0) license, which permits others to distribute, remix, adapt, build upon this work non-commercially, and license their derivative works on different terms, provided the original work is properly cited, appropriate credit is given, any changes made indicated, and the use is non-commercial. See: http://creativecommons.org/licenses/by-nc/4.0/.

\section{ORCID iD}

Alan Vernec http://orcid.org/0000-0002-7127-192X

\section{REFERENCES}

1 Vlad RA, Hancu G, Popescu GC, et al. Doping in sports, a never-ending story? Adv Pharm Bull 2018;8:529-34.

2 Donovan RJ, Egger G, Kapernick V, et al. A conceptual framework for achieving performance enhancing drug compliance in sport. Sports Med 2002;32:269-84.

3 Hunt TM. Routledge Handbook of Drugs and Sport: 1st Edition. In: Møller V, Hoberman J, eds. Routledge Handbook of Drugs and Sport. Anti-Doping Policy before, 1999. https://www.routledge.com/Routledge-Handbook-of-Drugs-and-Sport-1stEdition/Moller-Waddington-Hoberman/p/book/9780415702782. (accessed 10 Jan 2020)

4 Ljungqvist A. Brief history of anti-doping. Med Sport Sci 2017;62:1-10.

5 Fraser AD. Doping control from a global and national perspective. Ther Drug Monit 2004:26:171-4.

6 Fitch KD. Therapeutic use exemptions (TUEs) at the Olympic Games 1992-2012. Br J Sports Med 2013;47:815-8.

7 Personal communication with Gleaves J. A moral examination of the therapeutic use exemption in anti-doping. J Olymp Stud 2020.

8 WADA. World anti-doping code, 2019. Available: https://www.wada-ama.org/sites/ default/files/resources/files/wada_anti-doping_code_2019_english_final_revised_ v1 linked.pdf [Accessed 12 Jan 2020].

9 WADA. International standard for therapeutic use Exemptions (ISTUE), 2019. Available: https://www.wada-ama.org/sites/default/files/resources/files/istue_2019 en_new.pdf [Accessed 12 Jan 2020].

10 RT News. 70\% of Norwegian Olympic skiing medals won by asthmatics - Swedish documentary. RT Sports News, 2018. Available: https://www.rt.com/sport/418239norwegian-olympic-skiing-asthma-diagnosed/ [Accessed 12 Jan 2020]

11 Ruiz RR. Putin proposes distinct category for athletes on drug Exemptions. N. Y. Times, 2016. Available: https://www.nytimes.com/2016/10/12/sports/vladimir-putin-russiadoping.html [Accessed 12 Jan 2020].

12 Millar D. How to get away with doping. N. Y. Times, 2016. Available: https://www. nytimes.com/2016/10/16/opinion/sunday/how-to-get-away-with-doping.html [Accessed 12 Jan 2020]

13 Overbye $\mathrm{M}$, Wagner U. Between medical treatment and performance enhancement: an investigation of how elite athletes experience therapeutic use Exemptions. Int J Drug Policy 2013;24:579-88.

14 WADA Foundation Board (2018), 9.1 Health, medical and research Committee chair report. Minutes of the WADA Foundation board meeting 17 May 2018. Available: https://www.wada-ama.org/sites/default/files/resources/files/foundation_board_ meeting_minutes_17052018.pdf [Accessed 12 Jan 2020].

15 Canadian Institutes of health research, natural sciences and engineering Research Council of Canada, social sciences and humanities Research Council of Canada. Tri-Council policy statement: ethical conduct for research involving humans, 2014 Available: http://www.frqnt.gouv.qc.ca/documents/10191/186009/TCPS2.+pdf/ 6a8ab915-431b-428d-aa86-b22ca5c78053

16 WADA. The Prohibited list, 2019. Available: https://www.wada-ama.org/sites/default/ files/wada_2019 english_prohibited list.pdf [Accessed 12 Jan 2020].

17 Bernard $A \bar{B}$, Busse MR. Who wins the Olympic games: economic resources and medal totals. Rev Econ Stat 2004:86:413-7.

18 Vagenas G, Vlachokyriakou E. Olympic medals and demo-economic factors: novel predictors, the ex-host effect, the exact role of team size, and the "population-GDP" model revisited. Sport Manag Rev 2012;15:211-7.

19 United Nations GDPs of countries from December, 2017. Available: https://unstats.un. org/unsd/snaama/Basic [Accessed 12 Jan 2020].

20 McKenzie DC, Fitch KD. The asthmatic athlete: inhaled beta-2 agonists, sport performance, and doping. Clin J Sport Med 2011:21:46-50.

21 Bradley RA, Terry ME. Rank analysis of incomplete block designs: I. The method of paired comparisons. Biometrika 1952:39:324-45

22 Glickman ME, Stern HS. A State-Space model for national football League scores. J Am Stat Assoc 1998;93:25-35.

$23 \mathrm{GM} \mathrm{E}$, Jonathan $\mathrm{H}$. A stochastic rank ordered logit model for rating multi-competitor games and sports. J Quant Anal Sports 2015;11:131-44.

24 Lomax M. Airway dysfunction in elite swimmers: prevalence, impact, and challenges. Open Access J Sports Med 2016:7:55-63.

25 Fitch KD. An overview of asthma and airway hyper-responsiveness in Olympic athletes Br J Sports Med 2012:46:413-6.

26 Carlsen $\mathrm{K}-\mathrm{H}$. Sports in extreme conditions: the impact of exercise in cold temperatures on asthma and bronchial hyper-responsiveness in athletes. $\mathrm{Br} J$ Sports Med 2012:46:796-9.

27 Fitch KD, Sue-Chu M, Anderson SD, et al. Asthma and the elite athlete: summary of the International Olympic Committee's consensus Conference, Lausanne, Switzerland, January 22-24, 2008. J Allergy Clin Immunol 2008;122:254-60. 260.e1-7. 


\section{Original research}

28 International Olympic Committee's Consensus-Statement on Asthma in Elite Athletes. Available: https://stillmed.olympic.org/media/Document\%20Library/OlympicOrg//OC/ Who-We-Are/Commissions/Medical-and-Scientific-Commission/EN-IOC-ConsensusStatement-on-Asthma-in-Elite-Athletes.pdf [Accessed 12 Jan 2020].

29 Bougault $\mathrm{V}$, Turmel J, Boulet L-P. Bronchial challenges and respiratory symptoms in elite swimmers and winter sport athletes: airway hyperresponsiveness in asthma: its measurement and clinical significance. Chest 2010;138:31S-7.
30 Cookson WOC, Moffatt MF. Genetics of complex airway disease. Proc Am Thorac Soc 2011:8:149-53.

31 Vernec A, Slack A, Harcourt PR, et al. Glucocorticoids in elite sport: current status, controversies and innovative management strategies-a narrative review. $\mathrm{Br} J$ Sports Med 2020;54:8-12.

32 Greenland S, Schwartzbaum JA, Finkle WD. Problems due to small samples and sparse data in conditional logistic regression analysis. Am J Epidemiol 2000;151:531-9. 